\title{
Market opportunities do not explain the ability of herders to meet livelihood objectives over winter on the Mongolian Plateau
}

\author{
BAI Haihua ${ }^{1}$, YIN Yanting ${ }^{1}$, Jane ADDISON ${ }^{2}$, HOU Yulu ${ }^{3}$, WANG Linhe ${ }^{4}$, HOU Xiangyang ${ }^{1 *}$ \\ ${ }^{1}$ Grassland Research Institute, Chinese Academy of Agricultural Sciences, Huhhot 010010, China; \\ ${ }^{2}$ CSIRO Land and Water, ATSIP, James Cook University, Townsville 4811, Australia; \\ ${ }^{3}$ Agriculture Information Institute, Chinese Academy of Agricultural Sciences, Beijing 100081, China; \\ ${ }^{4}$ College of Ecology and Environmental Science, Inner Mongolia Agricultural University, Hohhot 010018, China
}

\begin{abstract}
Drylands under pastoral land use are considered one of the most vulnerable social-ecological systems to global climate change, but the herders' abilities to adapt to the different extreme weather events have received little attention in the drylands. Herders on the Mongolian Plateau (MP; including Inner Mongolia Autonomous Region of China and Mongolia), have had a long history of adapting climatic variability and extreme weather events. However, it is unclear how changes such as increased levels of infrastructure and market integration affect the ability of herders to achieve the key livelihood objectives: the minimisation of the death and abortion rates of livestock in the winter. Here, we used remotely sensed and household survey data to map, model and explore the climate exposure and sensitivity of herders in the settled area (Inner Mongolia of China) and nomadic area (Mongolia) in the winter of 2012-2013. We aimed to quantify the multi-scaled characteristics of both climate exposure and sensitivity through the lens of key adaptive strategies utilized by herders. Our results showed that the higher levels of infrastructure and market integration, and the lower levels of remoteness on the MP did not increase the herders' ability to achieve the key livelihood objectives. Our results also suggested that exposure to the snow that is comparatively greater than the long-term average (cumulative exposure) may be more important in determining the social-ecological vulnerability than absolute exposure. We suggested that neither the risk management strategies available to these herders, nor the demographic variables, could compensate for the mode of production governing the pastoral systems. Our study could provide further evidence for the complex and scaled nature of climate exposure and sensitivity, and the results imply that any analysis of the relationship among exposure, sensitivity and vulnerability of pastoral households to climate change in the drylands will require a multi-scaled and interdisciplinary approach.
\end{abstract}

Keywords: climate change; extreme weather events; adaptive strategies; vulnerability; households; winter; livelihood

Citation: BAI Haihua, YIN Yanting, Jane ADDISON, HOU Yulu, WANG Linhe, HOU Xiangyang. 2020. Market opportunities do not explain the ability of herders to meet livelihood objectives over winter on the Mongolian Plateau. Journal of Arid Land, 12(3): 522-537. https://doi.org/10.1007/s40333-020-0122-6

\section{Introduction}

Drylands constitute about $41 \%$ of the global landmass, home to about $38 \%$ of the world's

\footnotetext{
*Corresponding authors: HOU Xiangyang (E-mail: houxy16@vip.126.com)

The first and second authors contributed equally to this work.

Received 2018-05-28; revised 2019-08-27; accepted 2019-10-10

(C) Xinjiang Institute of Ecology and Geography, Chinese Academy of Sciences, Science Press and Springer-Verlag GmbH Germany, part of Springer Nature 2020
} 
population, and are considered to be amongst the most vulnerable areas to global climate change (World Health Organization, 2005; Moran et al., 2005; Pachauri and Reisinger, 2007; Twyman et al., 2011). The Intergovernmental Panel on Climate Change (IPCC) predicted a $2{ }^{\circ} \mathrm{C}$ warming and subsequent loss of soil moisture over the drylands (Watson et al., 2001). The complex and multiscaled interactions among exposure to climatic stressors, the magnitude and rate of climatic variation, and sensitivity (i.e., the degree to which a system is affected by climatic stressors) (Pachauri and Reisinger, 2007), are usually recognized from social-ecological systems (Spickett et al., 2008; Langton et al., 2012). In the global drylands, however, the already high levels of climatic variability may interact with the physical, biological and socio-economic factors to amplify such complexity (Fernandez-Gimenez et al., 2012). Despite the expected high levels of vulnerability to climate change, the effects of specific weather events on social-ecological systems of drylands have received little attention.

Significant uncertainty associated with future climate-related events, resource management, livelihoods and other key determinants of vulnerability (Kelly and Adger, 2000) are known to differ across socio-economic profiles, as well as by hazard type (Stern et al., 2013). This reinforces the need for a context-specific analysis of exposure, sensitivity and adaptive strategies of pastoral households to climatic variability (Spickett et al., 2008; Hallegatte, 2009). Comparisons of climate exposure and sensitivity across Mongolian Plateau (MP; including Inner Mongolia Autonomous Region of China and Mongolia) could help identify the physical, biological and socio-economic factors that contribute to climate change vulnerability. The MP provides an ideal case study area to explore the potential impacts of different weather events on the livelihood of herders in drylands with pastoral land use.

IPCC predicted that in East Asia, precipitation is likely to increase in both winter and summer, with a concurrent increase in the frequency of intense precipitation (Christensen et al., 2013). However, some studies concluded that precipitation, including spring precipitation, has declined in areas such as Inner Mongolia (Liu et al., 2005). It is likely that a hot period in summer will last longer and become more intense and frequent, and there is some evidence showing that temperature has already increased over the last 30 a (Addison, 2012). There has also been an increase in extreme weather events, such as intensive precipitation (Liu et al., 2005; Ranjeet et al., 2013). Winter is likely to be warmer and to have greater precipitation (Christensen et al., 2013). However, the complex feedback loops mean that we may never know enough about the relationships among the temporal and spatial scales of impacts, the projected climate changes and the resources upon which pastoral livelihoods are based. For example, Ranjeet et al. (2013) linked the combined summer drought-dzud event of 2009-2010 with the subsequent increase in grass biomass and canopy cover that may be needed for the long-term sustainability of the pastoral resources, but at the same time, this natural event caused a significant decline in pastoral livelihoods. It is unclear how changes in climate change will affect the livelihood strategies of the primary resource users on the MP.

Herders on the MP have had a long history of adapting to climatic variability and extreme weather events, such as dzud or the comparable 'snow disaster' (Middleton et al., 2014). Historically, livestock mobility has been an important adaptive strategy to adapt to the extreme weather events (Upton, 2012; Wang et al., 2013), which reduces the death rates of livestock effectively (Middleton et al., 2014). Despite the application of local ecological knowledge to adapt extreme weather events (Marin, 2010; Middleton et al., 2014), variations in the mode of production have shifted the nature of herders' sensitivity to climate change across the MP.

In Inner Mongolia of China, the Household Contract Responsibility System (HCRS) has been in place since the 1980s, with pastures allocated exclusively to each household through the contract. Since then, the non-mobility strategy for adapting climatic variability has become widespread, mainly including storage of feed, livelihood diversification and market exchange (Wang et al., 2013; Addison and Brown, 2014). Because Inner Mongolia is a significant source of the sandstorm material that affects Beijing and Tianjin, the Chinese government has implemented a number of different projects aiming at grassland management. For example, the Beijing-Tianjin Sandstorm Source Control Project includes the grazing bans and the enforced seasonal and rotational grazing practices. In parallel to the implementation of these projects, land use has become more reliant on 
material inputs with an increase in local fodder production, stall-feeding and fencing. Off-farm income has also become more importance (Wang et al., 2013; Zhen et al., 2014), but the social, economic and environmental impacts of these strategies are somewhat mixed (Addison and Greiner, 2016) and even controversial at some times (Yeh, 2013).

In Mongolia, mobility is affected by the mode of production (Fernandez-Gimenez et al., 2012; Addison and Brown, 2014), with a consequent decrease in distance and frequency of migration in some areas (Olonbayar, 2010). These complex changes have significantly affected the adaptive practice of long-distance mobility: 'otor' (Li and Huntsinger, 2011; Lkhagvadorj et al., 2013; Murphy, 2014). Growing wealth disparities also led to differentiated mobility patterns (Marin, 2010; Upton, 2012), which increased the exposure to volatile livestock markets (Addison and Brown, 2014), weakened the effects of the mode of production (Sternberg, 2010; FernandezGimenez et al., 2012; Middleton et al., 2014), and changed the nature of relief aid (FernandezGimenez et al., 2012). Further, the government support for livestock husbandry has declined since the transition of country's economy, with the responsibility for managing climatic risks increasingly devolving to individual pastoral households.

The factors that are linked to the increasing vulnerability of herders to climate change are also pertinent to the MP, such as remoteness (Spickett et al., 2008), the transition from nomadic to sedentary style of production (in the case of Inner Mongolia of China) (Ford, 2012), subsistence agriculture (Morton, 2007), poor infrastructure (Costello et al., 2009), high resource dependency (Adger, 1999) and low levels of financial capital (Adger, 1999; Leichenko and Silva, 2014). However, the impacts of increased levels of infrastructure and market integration relative to other strategies on minimizing the death and abortion rates of livestock over winter on the MP deserve further exploration.

In this study, we compared the climate exposure and sensitivity of herders in the settled area (Inner Mongolia of China) and nomadic area (Mongolia) in the winter of 2012-2013 on the MP. We aimed to quantify the multi-scaled nature of both climate exposure and sensitivity through the lens of herders' concern: the ability of livestock to both survive and reproduce in the winter. We hypothesize that the higher levels of infrastructure and market integration-related adaptation options available to the herders in the settled and nomadic areas would reduce their vulnerability to extreme weather events in the winter.

\section{Materials and methods}

\subsection{Study area}

This study was conducted in the settled area (Inner Mongolia of China) and nomadic area (Mongolia) on the MP. A total of eleven study sites were set on the MP, including six banners (Taibus, Duolun, Zhenglan, Xilinhot, Abag and West Ujimqin) in Inner Mongolia of China and five soums (Bayangol, Batnorov, Undurkhaan, Sukhbaatar and Bayandelger) in Mongolia. The eleven sites span the Eastern Eurasian Steppe Transect (EEST; $39^{\circ}-59^{\circ} \mathrm{N}, 108^{\circ}-115^{\circ} \mathrm{E}$; Han et al., 2014) with the total length of $1400 \mathrm{~km}$. From south to north of the EEST, the elevation varies from 800 to $2000 \mathrm{~m}$. The dominant precipitation occurs in summer and it increases towards the north and east. Mean annual precipitation along the EEST varies from $196 \mathrm{~mm}$ in Bayandelger to $386 \mathrm{~mm}$ in Duolun. Temperatures are low and show a significant intra-annual variability. Mean daily maximum temperature varies from $7.1^{\circ} \mathrm{C}$ in Sukhbaatar to $9.5^{\circ} \mathrm{C}$ in Duolun. Livestock grazing is the primary form of land use, with livestock mainly including sheep, goats and horses.

In the settled area, grazing prohibition is applied in Taibus and Duolun. Specifically, grazing is prohibited for the whole growing season in Taibus and for three months (from 10 March to 10 June) in Duolun. These two sites have high population densities, large area of farmland and high levels of infrastructure. For the two sites, farmers and herdsmen can easily access to the markets compared with other sites. Livestock husbandry in the settled area is significantly more intensive than that in the nomadic area, especially in Taibus, Duolun and Zhenglan, which are agro-pastoral areas.

All sites in the nomadic area are characterized by extensive pastoralism. Undurkhaan and 
Bayangol are the closet to Ulaanbaatar, the capital of Mongolia. Bayangol, in particular, is located within Mongolia's primary crop growing area. By contrast, other three sites, including Bayandelger, Batnorov and Sukhbaatar, are much farther from the Ulaanbaatar, with the first two sites being accessible to the capital via unpaved roads only.

\subsection{Methods}

Several methods have been used to assess the vulnerability of herders to climate change (Ford et al., 2010). Firstly, we investigated the spatial and temporal characteristics of climate exposure by assessing the key parameters that affect livestock production via constraints to grazing opportunities, including snow depth, and the total days and longest days of snow cover in the winter of 2012-2013. We also compared the snow depth in the winter of 2012-2013 with the mean value during the period of 2002-2012. Secondly, we analyzed the use of adaptive strategies by herders that may be linked to climate sensitivity. Thirdly, we used both the death and abortion rates of livestock to quantitatively explore herders' post-adaptation vulnerability to the winter of 20122013.

Climatic data were calculated at the remotely sensed pixel spatial scale $(24 \mathrm{~km} \times 24 \mathrm{~km})$, and socio-economic data were collected by household survey at the household scale. Subsequently, all these data were used to explore the factors that influence the death and abortion rates of small and large livestock on the MP.

\subsection{Climatic data}

We acquired meteorological data from National Agency for Meteorology and Environment Monitoring of Mongolia and Xilin Gol League Meteorological Agency of China (total of 30 meteorological stations, including 19 stations in nomadic area and 11 stations in settled area). Meteorological parameters included monthly mean temperature and precipitation of 1970-2010, and daily mean temperature, precipitation and snow depth of October 2012-April 2013.

The climatic data in the winter of 2012-2013 were processed by the Canadian Meteorological Center (CMC) to create snow depth figures at the spatial resolution of $24 \mathrm{~km} \times 24 \mathrm{~km}$. Further, the MODIS (MOD10A1) data from the US National Snow and Ice Data Center (NSIDC) at the spatial resolution of $500 \mathrm{~m}$ and temporal resolution of $8 \mathrm{~d}$ were used to calculate the total days and longest days of snow cover in the winter of 2012-2013. More detailed descriptions can be found in Riggs et al. (2006).

\subsection{Household survey}

A structured, open-ended household-level survey was conducted to assess the herders' preparedness for the winter of 2012-2013, their subsequent response via adaptive strategies and the impacts of snow on livestock. We used a stratified random sampling method to select the sampled households in each case study site. Before each interview, the researcher introduced and explained the reason for the survey in the same way. All the interviews were conducted with the verbal consent of herders. For each interview, the household head (or their representative if the head was not available) was interviewed in their native language. A total of 305 households were surveyed, with 170 in the settled area and 135 in the nomadic area. Table 1 shows the key empirical variables elicited during the survey. The survey questions included four main themes: (1) the basic demographic and socio-economic information, including the herder (e.g., age, gender and education) and household (e.g., grassland area and distance to the road) characteristics, livestock number and livestock income and cost; (2) the uptake of the selected adaptive strategies, including the reservation of fodder and forage, snow clearing and winter shelter size; (3) the government assistance in the winter of 2012-2013; (4) the perception of herders about the impact of extreme weather events in the winter of 2012-2013 on livestock production; and (5) the death and abortion rates of livestock.

\subsection{Statistical analyses}

Geographical indicators (area code, latitude and elevation), socio-demographic characters (age and education of herders), adaptive strategies (snow clearing, shelter area, total forage and total fodder), 
Table 1 Quantitative variables elicited during the household survey

\begin{tabular}{|c|c|}
\hline Variable & Measurement item \\
\hline Death rate & $\begin{array}{l}\text { Death rate of livestock (\%). Death rate_SL (1) and death rate_LL (1): death rate of small and large } \\
\text { livestock on the Mongolia Plateau, respectively. Death rate_SL (2) and death rate_LL (2): death rate } \\
\text { of small and large livestock in the settled area, respectively. Death rate_SL (3) and death rate_LL (3): } \\
\text { death rate of small and large livestock in the nomadic area, respectively. Death rate_SL (4) and death } \\
\text { rate_LL (4): death rate of small and large livestock in the three sites (Taibus, Zhenglan and Duolun) } \\
\text { in the settled area, respectively. Death rate_SL (5) and death rate_LL (5): death rate of small and large } \\
\text { livestock in Bayangol in the nomadic area, respectively. }\end{array}$ \\
\hline Abortion rate & $\begin{array}{l}\text { Abortion rate of livestock (\%). Abortion rate_SL (1) and abortion rate_LL (1): abortion rate of small } \\
\text { and large livestock on the Mongolia Plateau, respectively. Abortion rate_SL (2) and abortion rate_LL } \\
\text { (2): abortion rate of small and large livestock in the settled area, respectively. Abortion rate_SL ( } 3 \text { ) } \\
\text { and abortion rate_LL (3): abortion rate of small and large livestock in the nomadic area, respectively. } \\
\text { Abortion rate_SL (4) and abortion rate_LL (4): abortion rate of small and large livestock in the three } \\
\text { sites (Taibus, Zhenglan and Duolun) in the settled area, respectively. Abortion rate_SL (5) and } \\
\text { abortion rate_LL (5): abortion rate of small and large livestock in Bayangolin in the nomadic area, } \\
\text { respectively. }\end{array}$ \\
\hline Area code & The settled area $=1$, and the nomadic area $=2$. \\
\hline Latitude & Latitude $\left({ }^{\circ} \mathrm{N}\right)$. \\
\hline Elevation & Elevation above the sea level (m). \\
\hline Education & $\begin{array}{l}\text { Highest education level of interviewers, which was classed into the following categories: } 0=\text { no } \\
\text { education; } 1=\text { primary school; } 2=\text { junior high school; } 3=\text { senior high school; and } 4=\text { college education. }\end{array}$ \\
\hline Age & Age (a). \\
\hline Snow clearing & $\begin{array}{l}\text { Presence of government facilitated clearing of snow around the homestead and winter shelter. } 1 \text {, if } \\
\text { there is snow clearing by government; } 0 \text {, otherwise. }\end{array}$ \\
\hline Shelter area & Total floor area of winter shelter $\left(\mathrm{m}^{2}\right)$. \\
\hline Total forage & Total dry weight of forage self-prepared and purchased by the household $(\mathrm{kg})$. \\
\hline Total fodder & Total dry weight of fodder grown with or without irrigation and cut by the household (kg). \\
\hline Livestock number & Number of livestock owned by the household through the winter (sheep units). \\
\hline Snow depth & Snow depth in January $(\mathrm{cm})$. \\
\hline Access to road & Distance from households to the nearest road $(\mathrm{km})$. \\
\hline
\end{tabular}

livestock number, snow depth and access to the road were regarded as independent variables (Table 1). We performed a multi-regression analysis by using SPSS 19.0 (IBM, Amund, NY, USA) to explore the variables that were most related to the death and abortion rates of livestock. We used the ArcGIS 9.3 software (ESRI, RedLands, USA) to draw the figures of snow indicators, mainly including the spatial and temporal distributions of snow depth, the total days and longest days of snow cover, and the standard deviation between the snow depth in the winter of 2012-2013 and the mean snow depth during the period of 2002-2012.

\section{Results}

\subsection{Climate exposure: how did snow cover manifest through space and time?}

Snow depth varied spatially and temporally throughout the study area in the winter of 2012-2013 (Fig. 1). Early snow fell in October in the nomadic area while the settled area received little snow until November. Snow depth declined in the nomadic area between October and November and began to increase in November across the study area. All the study sites recorded an increasing snow depth from December 2012 to February 2013, with the latter being the deepest across the study period. In October 2012, the deepest snow was observed in Batnorov.

In the settled area, the snow was moderately deep across the central parts (Xilinhot and Abag), but much deeper in the southern (Zhenglan, Duolun and Taibus) and eastern (West Ujimqin) parts in November 2012. In December 2012, the snow was relatively deep in the southern (Zhenglan, 
Duolun and Taibus) and eastern (West Ujimqin) parts of the settled area and in Bayangol and Sukhbaatar of the nomadic area. This pattern was held in January and February of 2013. By March 2013, snow depth had declined significantly across the whole study area with the exception of sites West Ujimqin and Abag in the settled area, as well as sites Bayangol, Undurkhaan and Batnorov in the nomadic area. By April 2014, the snow still remained in West Ujimqin and Batnorov because it has not yet all melted in these study sites.
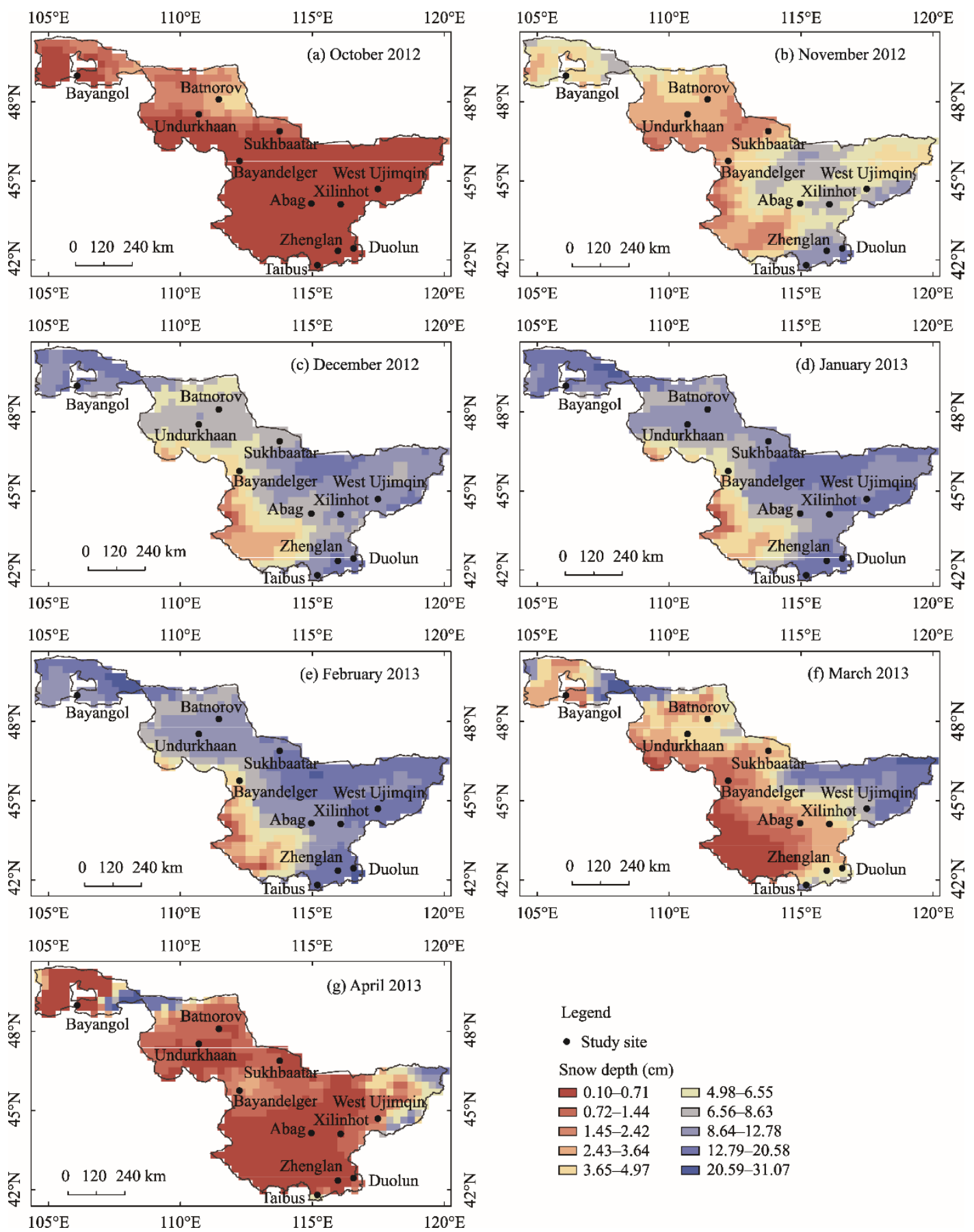

Legend

- Study site

Snow depth $(\mathrm{cm})$

$\square 0.10-0.71 \square 4.98-6.55$

$\square 0.72-1.44 \square 6.56-8.63$

$\square$ 1.45-2.42 $\square$ 8.64-12.78

$\square 2.43-3.64 \square 12.79-20.58$

$\square$ 3.65-4.97 $\square$ 20.59-31.07

Fig. 1 Spatial and temporal distributions of snow depth in the winter of 2012-2013

Few study sites experienced snow disaster conditions in the winter of 2012-2013. Snow disaster 
is defined as a period in which the average depth of snow exceeds $21 \mathrm{~cm}$ in the high mountain and forest regions and $16 \mathrm{~cm}$ in the steppes (Middleton et al., 2014). Livestock death can occur at snow depths greater than $15 \mathrm{~cm}$. In the nomadic area, only Bayangol experienced a snow depth deeper than $21 \mathrm{~cm}$ within a short-term period. In the settled area, Taibus, Zhenglan, Duolun and West Ujimqin also experienced a deep snow for at least one month between October 2012 and April 2013. The three sites (Taibus, Zhenglan and Duolun) in the settled area had both high annual mean and winter temperatures, resulted in a relatively short-length period of snow cover. However, once the snow fell, it stayed deeper between November 2012 and February 2013 in the sites of Taibus, Zhenglan and Duolun than other sites. Compared with other sites in the settled area, the site West Ujimqin had a slightly different snow depth pattern. Specifically, the West Ujimqin maintained a moderate depth of snow by October 2012, earlier than other sites in the settled area. In March 2013, the West Ujimqin received an unusually deep snow depth than other sites in the settled area, and the snow began to melt by April 2013. As such, this study site only experienced a short-term period of snow disaster.

Snow depth and the duration of snow cover did not always correlate in the winter of 2012-2013. In the nomadic area, although Bayandelger did not experience a deep snow (Fig. 1), large areas had a long-term period of snow cover (Fig. 2a). In the settled area, the four sites (Taibus, Zhenglan, Duolun and West Ujimqin) with deep snow had different durations of snow cover, with a larger part receiving less than 15 consecutive days of snow cover (Fig. 2b). In the nomadic area, only Bayangol experienced both deep snow and prolonged snow cover, but the area was not large.
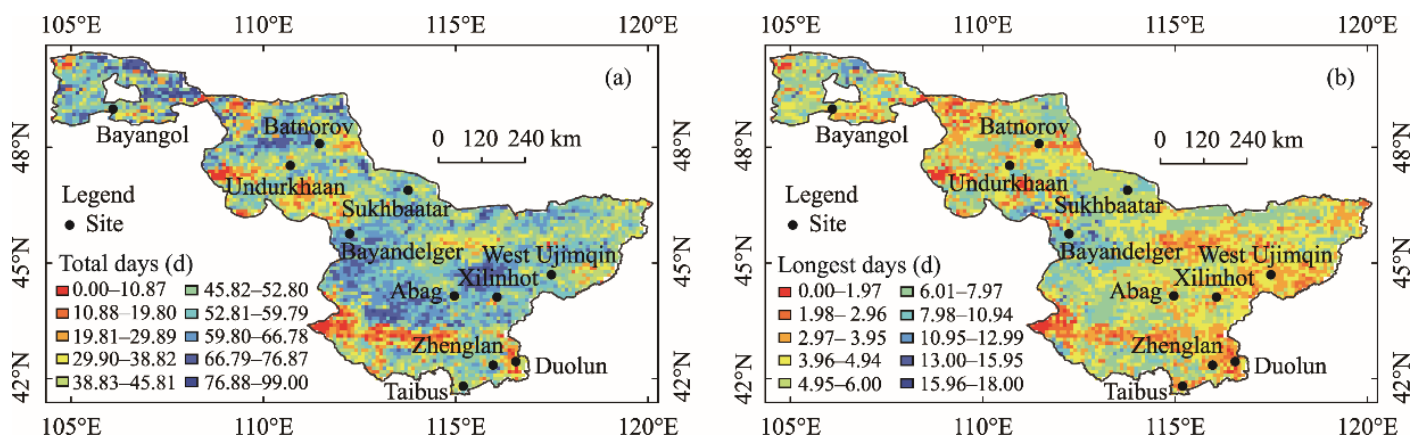

Fig. 2 Total days (a) and longest days (b) of snow cover in the winter of 2012-2013

We further compared the snow depth and the duration of snow cover in the winter of 2012-2013 with the average values of those during the period of 2002-2012, the results showed that the three sites (Taibus, Zhenglan and Duolun) in the settled area deviated much more than the sites in the nomadic area (Fig. 3). Between November 2012 and February 2013, these three sites had a significantly higher snow depth than the average snow depth of 2002-2012. Compared with the average value, the West Ujimqin also experienced a much deeper snow for almost five months. Bayangol in the nomadic area experienced a deep enough snow (which was categorized as the snow disaster as define by Middleton et al. (2014)), but this depth was still shallower than the average of the site. Despite the temporal anomaly, the snow exposure profile in the settled area (Taibus, Zhenglan and Duolun) and nomadic area (Bayangol) appeared similar enough to allow for spatial comparison of herder and livestock responses to the winter of 2012-2013.

\subsection{Key adaptive strategies utilized by herders in the winter of 2012-2013}

Values of parameters for the key adaptive strategies employed by herders were different among the study sites in the winter of 2012-2013 (Table 2). The use of winter shelters was one of the important management measures to adapt to the extremely low winter temperature. Shelter area was significantly greater $(P=0.027 ; n=279)$ in the settled area (mean $=121 \mathrm{~m}^{2}$, standard deviation $\left.(\mathrm{SD})=23 \mathrm{~m}^{2} ; n=170\right)$ than in the nomadic area (mean $\left.=89 \mathrm{~m}^{2}, \mathrm{SD}=36 \mathrm{~m}^{2} ; n=110\right)$. Similarly, the herders in the settled area utilized significantly higher amounts of the total $(P=0.000 ; n=304)$, selfcut $(P=0.000 ; n=304)$ and purchased $(P=0.000 ; n=303)$ fodder than the herders in the nomadic area. 

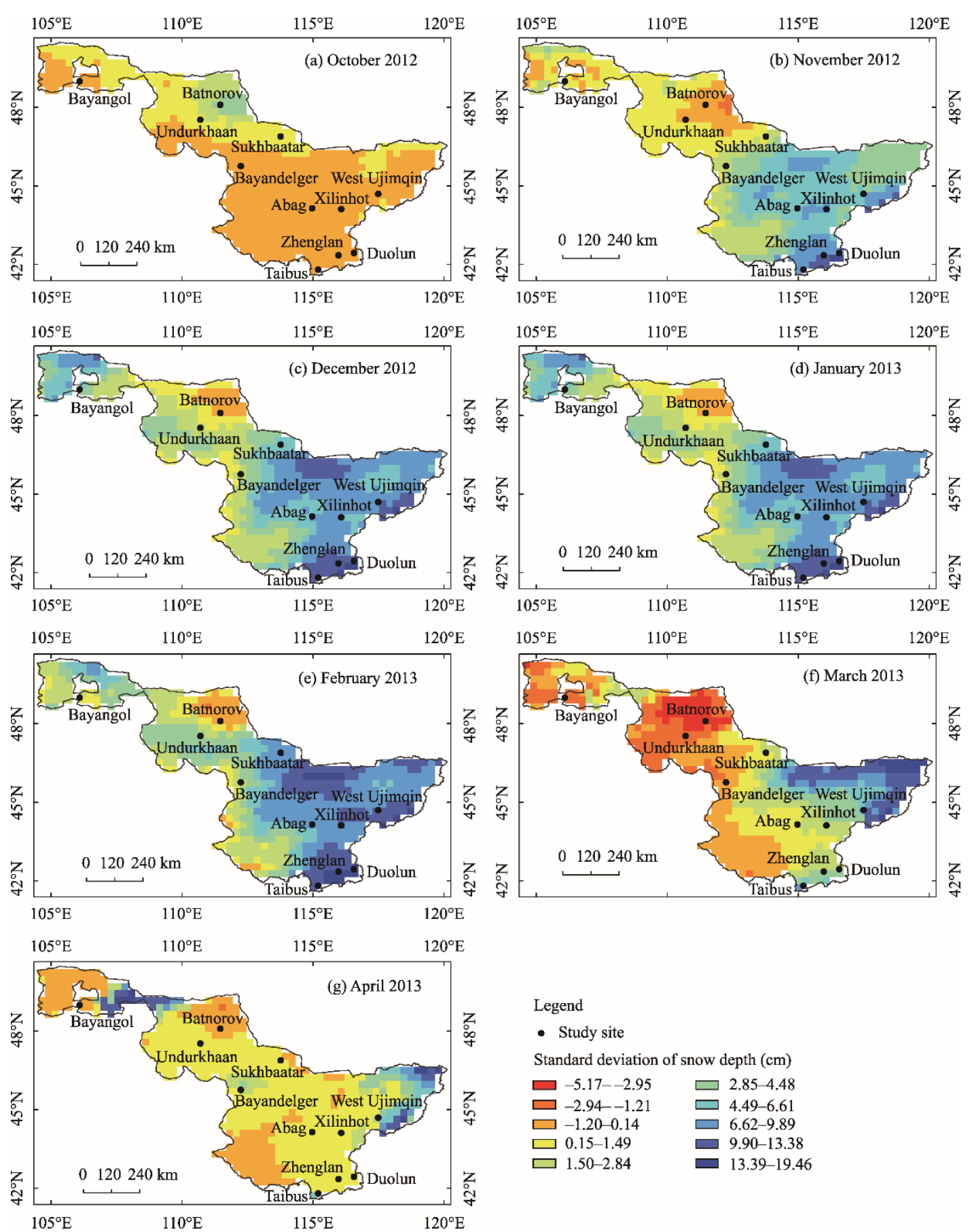

Legend

\section{- Study site}

Standard deviation of snow depth $(\mathrm{cm})$

$\begin{array}{ll}\square-5.17--2.95 & \square 2.85-4.48 \\ \square-2.94--1.21 & \square .49-6.61 \\ \square-1.20-0.14 & \square .62-9.89 \\ \square 0.15-1.49 & \square 90-13.38 \\ \square 1.50-2.84 & \square 13.39-19.46\end{array}$

Fig. 3 Standard deviation between the snow depth in the winter of 2012-2013 and the mean snow depth during the period of $2002-2012$

The total income was significantly and positively correlated with the total amount of purchased fodder $\left(R^{2}=0.326, P=0.000 ; n=304\right)$ and the total fodder utilized $\left(R^{2}=0.274, P=0.000 ; n=305\right)$. Levels of snow clearing from governments were significantly higher in the settled area than in the nomadic area $(P=0.000 ; n=304)$. In the settled area, about $68 \%$ of herders $(n=116)$ stated that snow had been cleared, while in the nomadic area, the percentage was only $38 \%(n=65)$. Income was also significantly $(P=0.002 ; n=304)$ higher and less variable among herders in the settled area (mean=156,047 CNY, SD=53,929 CNY; $n=170$ ) than in the nomadic area (mean=85,797 CNY, 
$\mathrm{SD}=24,221 \mathrm{CNY} ; n=135)$. Of the socio-demographic variables assessed, only education and income levels significantly varied between the settled and nomadic area. Education was significantly $(P=0.000 ; n=304)$ higher in the nomadic area than in the settled area, while income from livestock was significantly $(P=0.002 ; n=304)$ higher in the settled area than in the nomadic area.

Table 2 Comparisons of parameters for key adaptive strategies utilized by herders in the winter of 2012-2013

\begin{tabular}{|c|c|c|c|c|c|c|c|}
\hline Area & Site & $\begin{array}{c}\text { Proportion of } \\
\text { herders } \\
\text { impacted }(\%)\end{array}$ & $\begin{array}{c}\text { Snow clearing } \\
\text { percentage } \\
(\%)\end{array}$ & $\begin{array}{c}\text { Shelter } \\
\text { area }\left(\mathrm{m}^{2}\right)^{*}\end{array}$ & $\begin{array}{c}\text { Forage } \\
\text { per sheep } \\
\text { unit }(\mathrm{kg}) \\
\end{array}$ & $\begin{array}{c}\text { Fodder } \\
\text { per sheep } \\
\text { unit }(\mathrm{kg}) \\
\end{array}$ & $\begin{array}{l}\text { Livestock income } \\
(\mathrm{CNY})\end{array}$ \\
\hline \multirow[t]{7}{*}{ Settled area } & Taibus & 100 & 95 & $\begin{array}{c}143 \\
(0-300)\end{array}$ & $\begin{array}{c}125 \\
(0-333)\end{array}$ & $\begin{array}{c}43 \\
(4-181)\end{array}$ & $\begin{array}{c}60,618 \\
(5200-167,840)\end{array}$ \\
\hline & Duolun & 94 & 78 & $\begin{array}{c}110 \\
(0-300)\end{array}$ & $\begin{array}{c}204 \\
(0-333)\end{array}$ & $\begin{array}{c}44 \\
(5-108)\end{array}$ & $\begin{array}{c}49,919 \\
(0-180,240)\end{array}$ \\
\hline & Zhenglan & 97 & 69 & $\begin{array}{c}111 \\
(0-360)\end{array}$ & $\begin{array}{c}199 \\
(0-484)\end{array}$ & $\begin{array}{c}53 \\
(0-438)\end{array}$ & $\begin{array}{c}114,556 \\
(0-475,080)\end{array}$ \\
\hline & Xilinhot & 85 & 44 & $\begin{array}{c}110 \\
(30-600)\end{array}$ & $\begin{array}{c}125 \\
(0-191)\end{array}$ & $\begin{array}{c}17 \\
(1-78)\end{array}$ & $\begin{array}{c}232,199 \\
(50,700-630,656)\end{array}$ \\
\hline & Abag & 85 & 65 & $\begin{array}{c}125 \\
(0-400)\end{array}$ & $\begin{array}{c}95 \\
(0-450)\end{array}$ & $\begin{array}{c}26 \\
(0-150)\end{array}$ & $\begin{array}{c}207,351 \\
(21,400-660,120)\end{array}$ \\
\hline & West Ujimqin & 93 & 70 & $\begin{array}{c}129 \\
(0-400)\end{array}$ & $\begin{array}{c}122 \\
(0-350)\end{array}$ & $\begin{array}{c}18 \\
(2-130)\end{array}$ & $\begin{array}{c}194,805 \\
(20,375-772,800)\end{array}$ \\
\hline & Mean & 92 & 68 & $\begin{array}{c}121 \\
(0-600)\end{array}$ & $\begin{array}{c}141 \\
(0-484)\end{array}$ & $\begin{array}{c}33 \\
(0-438)\end{array}$ & $\begin{array}{c}156,047 \\
(0-772,800)\end{array}$ \\
\hline \multirow[t]{6}{*}{ Nomadic area } & Bayandelger & 31 & 23 & $\begin{array}{c}35 \\
(0-100)\end{array}$ & $\begin{array}{c}3 \\
(0-14)\end{array}$ & $\begin{array}{c}5 \\
(0-48)\end{array}$ & $\begin{array}{c}164,982 \\
(2704-1,244,745)\end{array}$ \\
\hline & Sukhbaatar & 50 & 46 & $\begin{array}{c}69 \\
(0-800)\end{array}$ & $\begin{array}{c}4 \\
(0-13)\end{array}$ & $\begin{array}{c}1 \\
(0-11)\end{array}$ & $\begin{array}{c}37,759 \\
(2272-102,370)\end{array}$ \\
\hline & Undurkhaan & 28 & 62 & $\begin{array}{c}115 \\
(0-600)\end{array}$ & $\begin{array}{c}11 \\
(1-15)\end{array}$ & $\begin{array}{c}2 \\
(0-21)\end{array}$ & $\begin{array}{c}34,149 \\
(4830-76,064)\end{array}$ \\
\hline & Batnorov & 10 & 52 & $\begin{array}{c}79 \\
(0-280)\end{array}$ & $\begin{array}{c}9 \\
(0-36)\end{array}$ & $\begin{array}{c}3 \\
(0-37)\end{array}$ & $\begin{array}{c}44,597 \\
(1080-193,345)\end{array}$ \\
\hline & Bayangol & 16 & 58 & $\begin{array}{c}159 \\
(0-900)\end{array}$ & $\begin{array}{c}80 \\
(5-694)\end{array}$ & $\begin{array}{c}15 \\
(0-144)\end{array}$ & $\begin{array}{c}155,947 \\
(1153-1,694,615)\end{array}$ \\
\hline & Mean & 27 & 38 & $\begin{array}{c}91 \\
(0-900)\end{array}$ & $\begin{array}{c}21 \\
(0-694)\end{array}$ & $\begin{array}{c}5 \\
(0-144)\end{array}$ & $\begin{array}{c}85,797 \\
(1081-1,694,615)\end{array}$ \\
\hline
\end{tabular}

Note: Values in the parentheses represent the range from the minimum to the maximum. ${ }^{*}$ means that winter shelters differed between the settled and nomadic areas. In the nomadic area, shelters were corrals with a partial roof and a compacted livestock dung floor; while in the settled area, shelters were constructed using typical bricks, and were generally more enclosed.

The sites of Taibus, Zhenglan and Duolun in the settled area and Bayangol in the nomadic area had similar weather conditions and exhibited a slightly different sensitivity profile to the winter of 2012-2013. Herders of the greatest snow exposure sites (Taibus, Zhenglan and Duolun) in the settled area purchased or self-cut significantly greater quantities of fodder than the herders of Bayangol in the nomadic area $(P=0.02 ; n=99)$, and these three sites had higher levels of snow clearing $(P=0.046 ; n=29)$. When the three greatest snow exposure sites were compared to other sites in the settled area, herders in the former derived less income from livestock $(P=0.000)$, obtained more clearing snow times $(P=0.017)$, purchased less forage $(P=0.000)$ and therefore utilized less forage per sheep unit overall $(P=0.002 ; n=170)$. When herders of Bayangol were compared to those of other sites in the nomadic area, we found that they had larger shelter areas $(P=0.012 ; n=135)$, more self-prepared forage $(P=0.000)$, greater total forage utilization $(P=0.000)$, fewer total livestock $(P=0.008)$ and therefore more forage per sheep unit $(P=0.041)$.

\subsection{Vulnerability}

3.3.1 Outcomes for livestock in the winter of 2012-2013

Death and abortion rates of livestock showed a consistent pattern among different study sites (Table $3)$. There were significant differences between the death and abortion rates of small and large livestock, with the settled area having an extremely significantly $(P<0.01)$ higher livestock loss than the nomadic area. In the settled area, the three sites of Taibus, Zhenglan and Duolun, which experienced a deep snow within a short-term period, had the highest death rates among all the study sites. In the nomadic area, Bayangol had the lowest death rates of both small and large livestock, 
despite being one of the four sites that experienced both deep snow and a long-term period of snow cover. Notably, small livestock had higher death rates than large livestock in all case study sites, with the death rates of large livestock being zero for the two sites in the nomadic area, i.e., Sukhbaatar and Bayangol.

Table 3 Death and abortion rates of small and large livestock in the winter of 2012-2013

\begin{tabular}{cccccc}
\hline \multirow{2}{*}{ Area } & Site & \multicolumn{2}{c}{ Death rate } & \multicolumn{3}{c}{ Abortion rate } \\
\cline { 3 - 6 } \cline { 4 - 5 } Settled area & Taibus & 0.173 & 0.026 & 0.034 & 0.033 \\
& Duolun & 0.111 & 0.043 & 0.031 & 0.045 \\
& Zhenglan & 0.080 & 0.048 & 0.055 & 0.055 \\
& Xilinhot & 0.077 & 0.001 & 0.069 & 0.003 \\
& Abag & 0.067 & 0.020 & 0.076 & 0.040 \\
West Ujimqin & 0.073 & 0.015 & 0.029 & 0.019 \\
& Mean & 0.089 & 0.025 & 0.053 & 0.036 \\
& Bayandelger & 0.031 & 0.019 & 0.045 & 0.030 \\
& Sukhbaatar & 0.050 & 0.000 & 0.099 & 0.074 \\
& Undurkhaan & 0.054 & 0.023 & 0.097 & 0.056 \\
& Batnorov & 0.034 & 0.002 & 0.007 & 0.037 \\
& Bayangol & 0.006 & 0.000 & 0.026 & 0.000 \\
& Mean & 0.033 & 0.006 & 0.019 & 0.006 \\
\hline
\end{tabular}

The proportion of herders whose livestock production was affected by the snow in 2012-2013 varied between the settled area and nomadic area, and to a lesser extent within each site. The herders in the nomadic area were less affected by the snow (mean=27\%, SD=12\%;n=131;P=0.000) than the herders in the settled area (mean $=92 \%, \mathrm{SD}=25 \% ; n=167)$. In the settled area, the proportion of herders affected by snow impact was largest in Taibus, Zhenglan and Duolun sites (experienced a deep snow within a short-term period), with herders accounting for $100 \%, 97 \%$ and $94 \%$ of the total interviewers, respectively. In the nomadic area, the proportion of herders affected by snow impact was low in Bayangol (experienced both deep snow and a long-term period of snow cover), with herders accounting for $16 \%$ of the total interviewers.

The proportions of herders that experienced the death and abortion rates of livestock due to the snow in 2012-2013 were also closely related. There were strong and positive correlations between the proportions of herders affected and the death rates of small livestock $\left(R^{2}=0.287, P=0.000\right.$; $n=298)$, death rates of large livestock $\left(R^{2}=0.168, P=0.004 ; n=298\right)$, abortion rates of small livestock $\left(R^{2}=0.136, P=0.019 ; n=298\right)$ and abortion rates of large livestock $\left(R^{2}=0.209, P=0.001 ; n=245\right)$. However, correlations between the measures of impact on livestock and the proportion of herders affected were significantly weaker when the data in the settled area and nomadic area were analyzed separately, with only the proportion of herders affected and the death rates of small livestock being positively and significantly correlated in the nomadic area $\left(R^{2}=0.207, P=0.020 ; n=126\right)$.

\subsubsection{Factors affecting livestock loss}

Latitude was significantly and negatively correlated with the death rates of small livestock in both the settled and nomadic areas. As shown in Table 4, the death rates of small livestock were significantly $(P<0.05)$ higher in more southerly sites in the settled area than in the nomadic area (Table 4), despite the higher amounts of fodder utilization, greater shelter area and higher levels of snow clearing in the settled area. Elevation had a significant positive relationship with the death rates of small and large livestock, with higher elevation leading to the larger overall death rates across the MP $(P<0.001)$. Notably, the sites in the settled area were at a higher elevation on average (mean $=1186 \mathrm{~m}, \mathrm{SD}=155 \mathrm{~m} ; n=170)$ than the sites in the nomadic area (mean=1037 $\mathrm{m}, \mathrm{SD}=118 \mathrm{~m}$; $n=134)$. Access to road had a significant negative correlation with the death rates of small livestock $(P<0.05)$ on the MP. The households who were closer to the roads had higher death rates of small livestock compared to those who were farther away from the roads. 


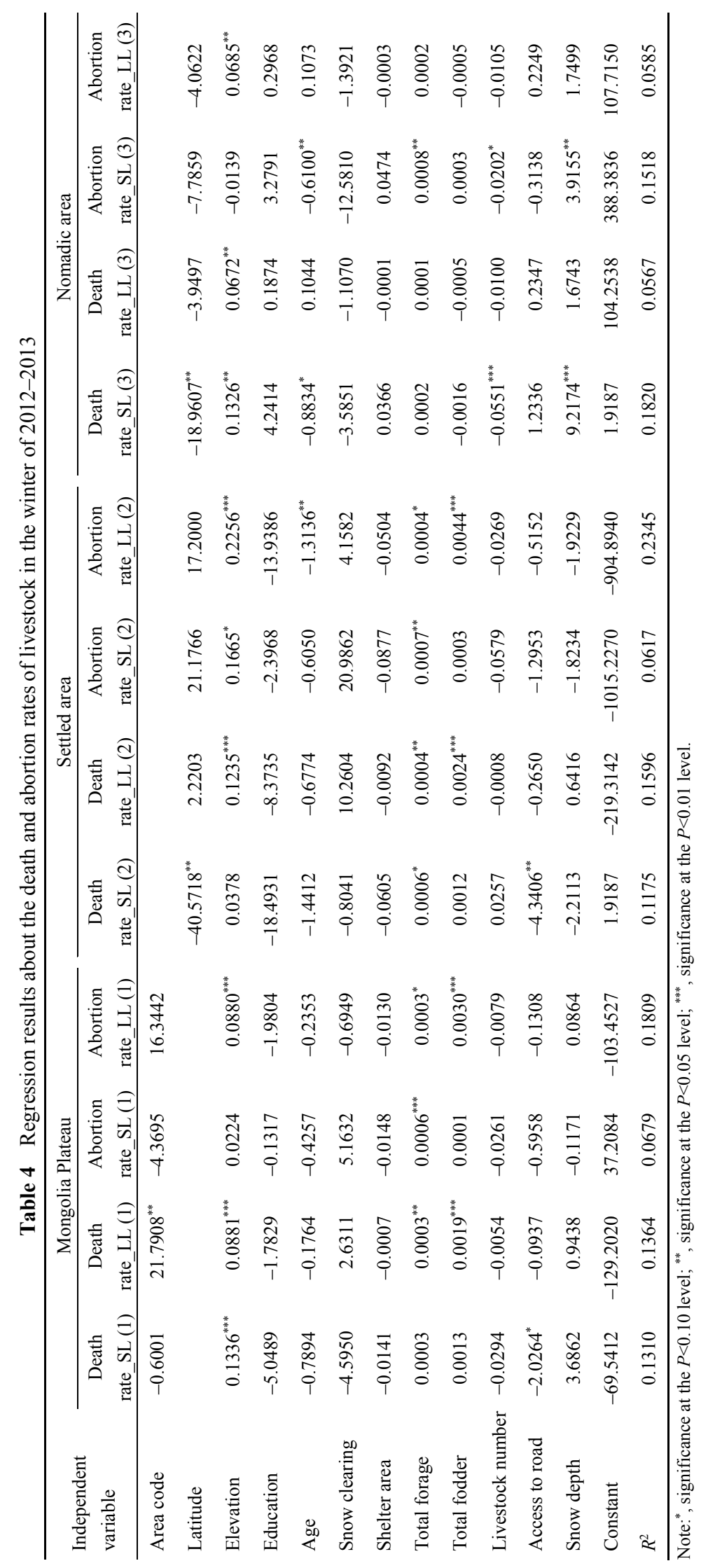


Regarding the MP as a whole, total forage and fodder were significantly $(P<0.05)$ positively related with the abortion rates, which means that herders with more forage and fodder had higher abortion rates of livestock. This is contrary to the common view that forage and fodder would contribute to adapting to snow disaster. However, when data were separately analyzed, total fodder was negatively correlated with the death rates of all livestock and abortion rates of large livestock in the nomadic area (albeit not statistically significantly).

For the three sites of Taibus, Zhenglan and Duolun in the settled area, the multi-regression using the same variables explored the significant factors influencing the abortion and death rates of both small and large livestock, as shown in Table 5. Latitude, education and age were significantly and negatively correlated with the death rates of small livestock $(P<0.05)$ in the settled area. Herders who live at higher latitudes (more northerly locales) and with higher education level and older age tended to have lower death rates of small livestock, while latitude and elevation had significant positive impacts on the death rates $(P<0.05)$ and abortion rates $(P<0.10)$ of large livestock, respectively. In terms of the adaptive strategies, shelter area was significantly and negatively related to the death rates of small livestock $(P<0.10)$, while total forage had a significant positive effect on the death rates $(P<0.10)$ and abortion rates $(P<0.01)$ of livestock. Herders with larger shelter area and less forage tended to have lower death and abortion rates of small livestock.

Table 5 Regression results regarding the death and abortion rates of livestock in Taibus, Zhenglan and Duolun in the settled area and in Bayangol in the nomadic area

\begin{tabular}{|c|c|c|c|c|c|c|c|c|}
\hline \multirow[b]{2}{*}{$\begin{array}{l}\text { Independent } \\
\text { variable }\end{array}$} & \multicolumn{4}{|c|}{ Settled area } & \multicolumn{4}{|c|}{ Nomadic area } \\
\hline & $\begin{array}{c}\text { Death } \\
\text { rate_SL (4) }\end{array}$ & $\begin{array}{c}\text { Death } \\
\text { rate_LL (4) }\end{array}$ & $\begin{array}{l}\text { Abortion } \\
\text { rate_SL (4) }\end{array}$ & $\begin{array}{l}\text { Abortion } \\
\text { rate_LL (4) }\end{array}$ & $\begin{array}{c}\text { Death } \\
\text { rate_SL (5) }\end{array}$ & $\begin{array}{l}\text { Death } \\
\text { rate_LL } \\
(5)\end{array}$ & $\begin{array}{l}\text { Abortion } \\
\text { rate_SL (5) }\end{array}$ & $\begin{array}{l}\text { Abortion } \\
\text { rate_LL } \\
(5)\end{array}$ \\
\hline Latitude & $-0.2611^{* *}$ & $1.0208^{* *}$ & -0.1407 & $1.0789^{*}$ & 0.0415 & - & $0.4415^{* * *}$ & - \\
\hline Elevation & -170.3728 & $116.9581^{* * *}$ & -29.2672 & $111.1882^{* *}$ & 89.9787 & - & 796.9826 & - \\
\hline Education & $-52.6690^{* *}$ & -12.4954 & -3.3546 & -13.3795 & 2.6314 & - & 24.9740 & - \\
\hline Age & $-3.4261^{*}$ & -1.1045 & 1.2161 & -1.1117 & -0.0207 & - & -0.2888 & - \\
\hline Snow clearing & -27.3267 & 21.5546 & 19.8439 & 26.0318 & 6.2191 & - & -29.0801 & - \\
\hline Shelter area & $-0.4477^{*}$ & -0.2076 & -0.1483 & -0.2367 & 0.0106 & - & 0.0774 & - \\
\hline Total forage & $0.0012^{*}$ & $0.0007^{*}$ & $0.0012^{* * *}$ & $0.0007^{*}$ & -0.0001 & - & -0.0005 & - \\
\hline Total fodder & 0.0048 & $0.0060^{* * *}$ & 0.0003 & $0.0062^{* * *}$ & 0.0001 & - & $0.0103^{*}$ & - \\
\hline $\begin{array}{c}\text { Livestock } \\
\text { number }\end{array}$ & -0.0539 & -0.1192 & 0.0131 & -0.1417 & 0.0065 & - & 0.0237 & - \\
\hline Access to road & $-6.3341^{*}$ & $-3.2693^{*}$ & -0.0547 & -3.2307 & 0.2663 & - & $-3.8890^{*}$ & - \\
\hline Snow depth & -11.8029 & 1.9742 & 10.4069 & 1.2794 & -9.2525 & - & $-98.2392^{* * *}$ & - \\
\hline Constant & 8139.3270 & -6236.0630 & 1213.7350 & -6051.7450 & -4343.2620 & - & $-38,271.3300$ & - \\
\hline$R^{2}$ & 0.2662 & 0.3091 & 0.2011 & 0.3015 & 0.1594 & - & 0.7307 & - \\
\hline
\end{tabular}

Note: ${ }^{*}$, significance at the $P<0.10$ level; ${ }^{* *}$, significance at the $P<0.05$ level; ${ }^{* * *}$, significance at the $P<0.01$ level; - , no value.

Similarly, for Bayangol in the nomadic area, access to road was significantly negatively related to the abortion rates of small livestock. For the Taibus, Zhenglan and Duolun in the settled area, access to road also had a significant negative impact on the death rates of small and large livestock with households closer to the roads having higher death rates of livestock. Snow depth was also significantly $(P<0.05)$ negatively correlated with the abortion rates of small livestock in Bayangol. The abortion rates were low despite high levels of exposure to deep and prolonged snowfall. Latitude and total fodder were significantly and positively related to the abortion rates of small livestock. The households who lived at lower latitude (more southerly locales) with less fodder had lower abortion rates of livestock.

There was little evidence suggesting that snow clearing, forage and fodder were significantly conducive to lower death or abortion rate of livestock. Only shelter area negatively affected the death and abortion rates of livestock in the settled area. That is, as expected, households with larger shelter areas had a lower livestock loss. In the nomadic area, however, shelter area was positively correlated with the death rates and abortion rates of small livestock, albeit not at a significant level. 


\section{Discussion}

\subsection{Implications of high spatial and temporal variability in exposure to snow cover}

Our analysis provided a snapshot of exposure to deep and prolonged snow cover on the MP in the winter of 2012-2013. Our results illustrated that, like drought (Sternberg et al., 2011), winter weather patterns can also be very spatially localized across the MP. These results concurred with the research of Middleton et al. (2014), which highlighted a similarly high level of spatial localization of the dzud during 2009-2010 in the nomadic area (western Mongolia).

Our results also suggested that exposure to the snow that is comparatively greater than the longterm average (cumulative exposure) may be more important in determining the social-ecological vulnerability of herders than absolute exposure herder's knowledge base, and ability to anticipate change and access feed resources can affect the adaptability of herders to climate change (Vincent, 2007). From the perspective of vulnerability to climate change, this suggests that a rethink of extreme weather events in winter is needed. Predicting absolute climate exposure will not always be enough to estimate herders' vulnerability on the MP as the scaled nature of exposure can facilitate or constrain learning and adaptation opportunities. Thus, climate exposure needs to be understood at a greater spatial and temporal scale, and the need to integrate the dynamics of climate-based predictors into vulnerability assessments cannot be overemphasized.

\subsection{Adaptive strategies and climate vulnerability when higher levels of infrastructure and market integration do not reduce sensitivity}

The geographical variables of elevation and latitude were strong predictors of livestock death, but these may be acting as surrogates for other geographically related variables that were not assessed in this study.

Herders' adaptive strategies and their ability to achieve livelihood objectives varied greatly between the settled and nomadic areas on the MP. These general differences were also revealed by Wang et al. (2013). However, our results conflict with Wang et al. (2013) who found that the death rates of livestock during 2000-2009 were much higher in the nomadic area than in the settled area under similar climate conditions. Wang et al. (2013) also suggested that lack of forage and herders' inability to migrate during harsh climate conditions were the main causes of livestock death, while our results confirmed a positive relationship between the forage and fodder purchased and the death and abortion rates of livestock. The positive relationship between the former and latter is likely to be a case of correlation rather than causation, reflecting the ineffective last minute 'panic' purchase of forage and fodder as livestock condition deteriorate. Total forage and total fodder were not significant predictors of abortion or death rates of livestock in the winter of 2012-2013 in both settled and nomadic areas. Herders who live closer to the roads and exhibit higher availability of commercial fodder and better infrastructure, did not generally have lower livestock death or abortion rates than those live in remote areas with poorer infrastructure. Instead, deviation from the mean climatic exposure appeared to be a stronger predictor of vulnerability than the uptake of potentially adaptive strategies. Self-motivated adaptive strategies such as the collection and storage of forage and fodder prior to winter did little to reduce the death and abortion rates of livestock.

We also found little evidence of the truism that herders with a lower level of knowledge are more likely to lose their livestock than the experienced herders with regard to the livestock-related risk that accompanies extreme weather events (Ericksen, 2014). Education, an indicator of herder's knowledge, was not a predictor of livestock loss in the winter of 2012-2013 in the either settled or nomadic area (except the three sites in the settled area: Taibus, Zhenglan and Duolun). However, age as an indicator of experience significantly negatively affected the abortion rate of large livestock in the settled area, and the death and abortion rates of small livestock in the nomadic area. This implies that households with older heads are likely to have lower livestock loss, but that was not always true for these two areas (settled and nomadic areas). The probable explanation is that age does not always act as a surrogate of local ecological knowledge (Souto and Ticktin, 2012), but our results also challenged the assertion that the current level of experiential local ecological knowledge accumulated by herders is sufficient to completely mitigate the risks presented by the 
current climate envelope.

Our data provided some support for the claim that a diverse herd minimizes the death rates of livestock during dzud, because the large livestock can be able to clear snow for the benefit of small livestock (Li et al., 2006; Han, 2007; Wang et al., 2009), but the percentage of large livestock in a herd was not a significant predictor of death rates when all data were combined for the nomadic or settled area. There was a significant negative relationship between the percentage of large livestock and the death rates of small livestock when the three most severely affected sites (Taibus, Zhenglan and Duolun) were analyzed separately. This suggests that during the periods of deep snow, a diverse herd may indeed reduce the vulnerability of small livestock.

\subsection{Limitations of the study}

Household vulnerability is a product of the temporal synchrony of biophysical and socio-economic factors (Ford et al., 2013). Temporary factors not examined in this study could have masked our results. One particularly important factor that was not examined as part of the suite of the assessed adaptive strategies, but may help explain the results, was mobility. Mobility could have positive effects on pasture condition (Wang et al., 2013), and it can help herders avoid climatic disasters, with subsequent reductions in livestock mortality (Middleton et al., 2014). Other comparisons between the settled and nomadic areas consistently identified higher levels of mobility in the latter region (Sneath, 1998; Addison, 2012; Wang et al., 2013). It is likely that Bayangol in the nomadic area had a higher mobility compared with the three similarly exposed sites (Taibus, Zhenglan and Duolun) in the settled area, where the households didn't migrate at all due to small area of grasslands. These three sites also had a high deviation from the long-term snow depth average. In the absence of a longitudinal study, the absolute effects of high death rate and low comparative deviation from long-term snow depth averages on the key livelihood strategies of maintaining and increasing livestock capital cannot be differentiated.

\section{Conclusions}

Our result showed that the higher levels of infrastructure and market integration-related adaptive strategies available to herders on the MP would not lead to a lower level of vulnerability to extreme weather events over winter. Household vulnerability to extreme weather events over winter on the MP cannot be simplistically linked to remoteness, lower access to markets and low levels of access to infrastructures such as roads. Geographical remoteness from significant urban areas may not be a suitable proxy for climate change vulnerability. Instead, our results suggested that the unexpectedness of weather patterns is a stronger factor driving the survival and reproduction of livestock. In a dryland context that is characterized by unexpectedness, the relative inability of the assessed adaptation options to overcome the impacts of unexpected exposure on households and livestock production should be of great concern. It is possible that too much reliance on adaptive strategies associated with lower levels of remoteness, such as the use of irrigated fodder, has generated a trajectory of maladaptation.

\section{Acknowledgements}

This research was funded by the Agricultural Science and Technology Innovation Program of Chinese Academy of Agricultural Sciences (CAAS-ASTIP-2020-IGR-04), the National Natural Science Foundation of China (71774162) and the International Science and Technology Program of China (2016YFE0116400). The authors would like to thank the herders who participated in the survey.

\section{References}

Addison J. 2012. Institutional settings, herder livelihoods and rangeland condition in the Gobi Desert. PhD Dissertation. Australia: University of Queensland.

Addison J, Brown C. 2014. A multi-scaled analysis of the effect of climate, commodity prices and risk on the livelihoods of Mongolian pastoralists. Journal of Arid Environments, 109: 54-64. 
Addison J, Greiner R. 2016. Applying the social-ecological systems framework to the evaluation and design of payment for ecosystem service schemes in the Eurasian steppe. Biodiversity and Conservation, 25(12): 2421-2440.

Adger W N. 1999. Social vulnerability to climate change and extremes in coastal Vietnam. World Development, 27(2): 249-269.

Christensen J H, Krishna K K, Aldrian E, et al. 2013. Climate phenomena and their relevance for future regional climate change. In: Climate Change 2013: The Physical Science Basis. Contribution of Working Group I to the Fifth Assessment Report of the Intergovernmental Panel on Climate Change. Cambridge: Cambridge University Press, 1240-1244.

Costello A, Abbas M, Allen A, et al. 2009. Managing the health effects of climate change. The Lancet, 373(9676): $1693-1733$.

Ericksen A. 2014. Depend on each other and don't just sit: The socialist legacy, responsibility, and winter risk among Mongolian herders. Human Organization, 73(1): 38-49.

Fernandez-Gimenez M E, Batkhishig B, Batbuyan B. 2012. Cross-boundary and cross-level dynamics increase vulnerability to severe winter disasters (dzud) in Mongolia. Global Environmental Change, 22(4): 836-851.

Ford J D, Keskitalo E C H, Smith T, et al. 2010. Case study and analogue methodologies in climate change vulnerability research. Wiley Interdisciplinary Reviews: Climate Change, 1(3): 374-392.

Ford J D. 2012. Indigenous health and climate change. American Journal of Public Health, 102(7): 1260-1266.

Ford J D, McDowell G, Shirley J, et al. 2013. The dynamic multiscale nature of climate change vulnerability: An Inuit harvesting example. Annals of the Association of American Geographers, 103(5): 1193-1211.

Gao Q, Zhang X S. 1997. A simulation study of responses of the North-east China transect to elevated $\mathrm{CO}_{2}$ and climate change. Ecological Applications, 7(2): 470-483.

Gonzalez-Megias A, Menéndez R. 2012. Climate change effects on above- and below-ground interactions in a dryland ecosystem. Philosophical Transactions B: Biological Sciences, 367(1606): 3115-3124.

Hallegatte S. 2009. Strategies to adapt to an uncertain climate change. Global Environmental Change, 19(2): $240-247$.

Han J. 2007. Meteorological factor analysis in snow disaster in the Middle East Pastoral areas of Inner Mongolia. Yinshan Academic Journal (Natural Science Edition), 21(3): 48-51. (in Chinese)

Han W J, Hou X Y, Olokhnuud C L, et al. 2014. The characteristics of plant communities along East Eurasian Steppe Transect. Journal of Integrative Agriculture, 13(6): 1157-1164.

Kelly P M, Adger W N. 2000. Theory and practice in assessing vulnerability to climate change and facilitating adaptation. Climatic Change, 47(4): 325-352.

Langton M, Parsons M, Leonard S, et al. 2012. National climate change adaptation research plan for indigenous communities. National Climate Change Adaptation Research Facility (NCCARF), Gold Coast, Australia.

Leichenko R, Silva J A. 2014. Climate change and poverty: Vulnerability, impacts and alleviation strategies. Climate Change, 5(4): 539-556.

Li H, Li X, Zhang H. 2006. Study about snow disaster grade in Chinese pastoral areas. Journal of Qinghai Meteorology, 1: 2427. (in Chinese)

Li W J, Huntsinger L. 2011. China's grassland contract policy and its impact on herder ability to benefit in Inner Mongolia: Tragic feedbacks. Ecology and Society, 16(2): 1-14.

Liu Y, Cai Q F, Shi J F, et al. 2005. Seasonal precipitation in the south-central Helan Mountain region, China, reconstructed from tree-ring width for the past 224 years. Canadian Journal of Forest Research, 35(10): 2403-2412.

Lkhagvadorj D, Hauck M, Dulamsuren C, et al. 2013. Pastoral nomadism in the forest-steppe of the Mongolian Altai under a changing economy and a warming climate. Journal of Arid Environments, 88: 82-89.

Marin A. 2010. Riders under storms: Contributions of nomadic herders' observations to analysing climate change in Mongolia. Global Environmental Changes, 20(1): 162-176.

Middleton N, Rueff H, Sternberg T, et al. 2014. Explaining spatial variations in climate hazard impacts in western Mongolia. Landscape Ecology, 30(1): 91-107.

World Health Organization (WHO). 2005. Ecosystems and human well-being: Health synthesis. In: A Report of the Millennium Ecosystem Assessment. World Health Organization. Geneva, Switzerland.

Moran E, Ojima D S, Buchman N, et al. 2005. Global land project: Science plan and implementation strategy. In: IGBP (International Geosphere Biosphere Program) Report No. 53/International Human Dimensions Programme Report No. 19. IGBP Secretariat, Stockholm.

Morton J F. 2007. The impact of climate change on smallholder and subsistence agriculture. Proceedings of the National Academy of Sciences, 104(50): 19680-19685.

Murphy D J. 2014. Ecology of rule: Territorial assemblages and environmental governance in rural Mongolia. Anthropological Quarterly, 87(3): 759-792.

Olonbayar M. 2010. Livelihood Study of Herders in Mongolia. Ulaanbaatar: Mongolian Society for Range Management, 11-16. 
Pachauri R K, Reisinger A. 2007. Climate Change 2007: Synthesis Report. Cambridge: Intergovernmental Panel on Climate Change, 25-28.

Ranjeet J, Chen J Q, Ouyang Z, et al. 2013. Vegetation response to extreme climate events on the Mongolian Plateau from 2000 to 2010. Environmental Research Letters, 8(3): 035033, doi: 10.1088/1748-9326/8/3/035033.

Riggs G A, Hall D K, Salomonson V V. 2006. MODIS snow products user guide to collection 5. Digital Media, 80(6): 1-80.

Sneath D. 1998. State policy and pasture degradation in Inner Asia. Science, 281(5380): 1147-1148.

Souto T, Ticktin T. 2012. Understanding interrelationships among predictors (age, gender and origin) of local ecological knowledge. Economic Botany, 66(2): 149-164.

Spickett J T, Brown H L, Katscherian D. 2008. Health Impacts of Climate Change: Adaptation Strategies for Western Australia. Perth: Western Australian Department of Health, 9-16.

Stern P C, Ebi K L, Leichenko R, et al. 2013. Managing risk with climate vulnerability science. Nature Climate Change, 3(7): 607-609.

Sternberg T. 2010. Unravelling Mongolia's extreme winter disaster of 2010. Nomadic Peoples, 14(1): $72-86$.

Sternberg T, Thomas D, Middleton N. 2011. Drought dynamics on the Mongolian steppe, 1970-2006. International Journal of Climatology, 31(12): 1823-1830.

Twyman C, Fraser E D G, Stringer L C, et al. 2011. Climate science, development practice, and policy interactions in dryland agroecological systems. Ecology and Society, 16(3): 14, doi: 10.5751/ES-04261-160314.

Upton C. 2012. Adaptive capacity and institutional evolution in contemporary pastoral societies. Applied Geography, 33(1): 135141.

Vincent K. 2007. Uncertainty in adaptive capacity and the importance of scale. Global Environmental Change, 17(1): 12-24.

Watson R T, Albritton D L, Barker T, et al. 2001. Climate Change 2001: Synthesis Report. Cambridge: Cambridge University Press, 44-48.

Wang J, Brown D G, Agrawal A. 2013. Climate adaptation, local institutions, and rural livelihoods: A comparative study of herder communities in Mongolia and Inner Mongolia, China. Global Environmental Change, 23(6): 1673-1683.

Wang Z, Sun Q, Chang B. 2009. Grassland Disaster. Beijing: China Agriculture Press, 188-191. (in Chinese)

Yeh E. 2013. The politics of conservation in contemporary rural China. The Journal of Peasant Studies, 40(6): 1165-1188.

Zhen L, Li F, Yan H M, et al. 2014. Herders' willingness to accept versus the public sector's willingness to pay for grassland restoration in the Xilingol League of Inner Mongolia, China. Environmental Research Letters, 9(4): 045003, doi: 10.1088/1748-9326/9/4/045003. 